\title{
The Impact of Patient \& System Specific Variables on Mortality Post Hip Fracture - A Mini Review
}

\author{
C Downey* and Quinlan JF \\ Department of Trauma \& Orthopedics, Tallaght University Hospital, Ireland
}

*Corresponding author : C Downey, Department of Trauma \& Orthopedics, Tallaght University Hospital, Ireland.

Received Date: March 20, 2019

Published Date: April 02, 2019

\begin{abstract}
Background: Hip fractures are common, costly and topical due to recent improvements in care secondary to national registries. Whilst each patient experiencing hip fracture is different, they share many variables. These variables can contribute to the individual's mortality risk, knowledge of which can highlight increased risk variables with care then organized to mitigate for same

Design: Narrative literature review using PubMed and Google Scholar

Results: 5 variables were reviewed.

- Gender; males mortality risk is approximately twofold compared to females,

- Age; HR 1.51 with increasing age, OR 2.11 for those aged 75-84 and OR 4.10 for those >85 years vs those aged 65-74 years,

- Nursing Home Residency; increased OR 3.56 \& RR 3.24 with regards to mortality,

- Time-to-Surgery; the evidence remains conflicting and

- Weekend Effect; the evidence is heterogenous and more studies are required.

Conclusion: This study highlights male gender, increasing age and nursing home admission source as high risk admission variables for mortality in the hip fracture cohort. Further studies are required to delineate the true impact of time-to-surgery and the weekend effect.
\end{abstract}

\section{Introduction}

\section{Mortality risk assessment}

Fragility hip fractures are both common and costly. Mortality post hip fracture has been reported previously at $10 \%$ at 30 -days and $30 \%$ at 1-year [1,2]. There have been a number of improvements regarding hip fracture care secondary to international audit in the form of national hip fracture registries. Data from the National Hip Fracture Database (UK) suggests a reduction in 30-day mortality secondary to audit [1].

Evidence based up-to-date information on mortality rates following hip fracture are important to guide

- Communication with the patient and their loved ones,

- Local and national risk management,

- $\quad$ Discharge planning and
- Internal and external benchmarking [3].

Recently, a number of research groups have developed weighted scoring systems with the aim of predicting mortality following fragility hip fracture. Examples of these prediction tools are the Nottingham Hip Fracture Score (NHFS) [3], Orthopedic Physiological and Operative Severity Score for the Enumeration of Mortality and Morbidity (O-POSSUM), Estimation of Physiologic Ability and Surgical Stress (E-PASS), Charlson Comorbidity Index (CCI), Almelo Hip Fracture Score (AHFS), Hip Fracture Estimator of Mortality Amsterdam (HEMA), Hip-Multidimensional Frailty Score (Hip-MFS), National Hip Fracture Database Risk Model (UK) and others by Jiang, et al. and Holt, et al. [3-10]. These tools differ in the patient's admission variables used to create each risk model.

In 2012, the Irish Hip Fracture Database was established to improve the quality of hip fracture care in Ireland. Since then, in 
each of the 16 operating hospitals in Ireland, there are number of variables recorded locally for each patient which suffers a fragility hip fracture [11]. A number of these independent variables feature repeatedly in medical literature due to their strength of correlation with mortality in this fragile patient cohort. Again, knowledge of evidence based up-to-date information is important to highlight patient and system specific variables associated with increased risk of mortality in this fragile cohort.

To this end, we hereby review the current literature with respect to

- Gender,

- $\quad$ Age,

- $\quad$ Admission source

- $\quad$ Time-to-surgery with regards to their relationship with mortality following fragility hip fracture.

\section{The weekend-effect}

The "weekend effect" is a hypothesis that patients admitted to hospital over the weekend have an increased risk of mortality than those admitted on weekdays [12]. This subject has become topical in the National Health Service UK as the British government introduce measures to implement their "seven day services" policy [13]. We hereby review the current literature on the "weekend effect" with regards to fragility hip fracture related mortality.

\section{The Review}

\section{Patient specific variables}

Gender: The literature regarding the ratios of female to male patients which suffer a fragility hip fracture is consistent at approximately $70: 30[14,15]$. Whilst it is well documented that both sexes have excess mortality post hip fracture, male gender has repeatedly been shown to have a greater mortality excess than females [15]. A large Norwegian study [16] involving 81,867 patients with fragility hip fracture concluded a 4.6 fold higher excess 1-year mortality in males and 2.8-fold excess in females versus age matched non-hip fracture controls whilst Kristensen, et al. [17] reported mortality in males as high as 2-fold higher compared to females. Similarly, Liu, et al. [18] reported an almost twofold increase (HR 1.91). A multitude of separate studies consistently describe the male gender as a risk factor for excess mortality following hip fracture [19-25].

Age: Age is a well-established risk factor for increased risk of mortality post hip fracture in both sexes [21-23,26,27] Liu, et al. [18] recently undertook a meta-analysis using 18 studies and a combined cohort of $\sim 224,000$ patients with fragility hip fractures and assessed the relationship between age and mortality. The authors concluded that there is a 1.51 increased risk of mortality (Hazard Ratio 1.51, p < 0.001) with increasing age. In order to elucidate the relationship between increasing age (by decade) and mortality post hip fracture, Padron-Monedero, et al. [28] undertook a cross sectional study of those aged $>65$ years which were hospitalized in Spain during 2013 with a fragility hip fracture. After adjusting for comorbidities, using the 65-74 year old cohort as a control group, the multivariate OR of mortality for those aged 75-84 was 2.11 and those aged $>85$ was 4.10 , showing a clear relationship between increasing age and mortality risk.

Admission source - nursing home residency: There have been a number of studies which have aimed to delineate a relationship between those who are admitted from a nursing home and mortality risk following fragility hip fracture. Holvik, et al. [29] sought to identify patient-related risk factors which predicted 1-year mortality in a local fragility hip fracture group $(n=567)$ and concluded that admission from a nursing home was an independent predictor for 1-year mortality (RR 3.24). Khan, et al. [30] undertook a similar study but focused on 30-day mortality post fragility hip fracture in a retrospective study including 467 patients. This group found that patients admitted from either nursing/residential home was an independent risk factor for early mortality (OR 3.56). Hannan, et al. [31] collected mortality outcomes at 6 months on a similar set of patients $(n=571)$. Whilst this group established a clear correlation between nursing home residency and post operative mobility at 6 months, they were unable to establish a similar relationship with mortality.

\section{System specific variables}

Time-to-surgery: There have been many studies published within the medical literature which have investigated "surgical waiting time" or "time-to-surgery" and mortality risk in the fragility hip fracture cohort. Whilst it appears that shorter timeto-surgery results in reduced rate of complications and length of stay, the outcomes regarding mortality risk are less conclusive. In 2010, Leung, et al. [32] performed a literature review including 42 peer-reviewed articles from 1980-2009. This group examined the relationships between "time-to-surgery" and both short and long term mortality. Having undertaken detailed analysis of the available literature, the group concluded that the evidence was conflicting and that there was no conclusive evidence upon which to base a strict recommendation.

More recently, Nyholm, et al. [33] found that surgical delay of $>12,>24$ and $>48$ hours increased 30 -day mortality respectively (OR 1.45, p = 0.02, OR 1.34, p = 0.02 and OR 1.56, $\mathrm{p}=0.02$ ). They also found 90 -day mortality increased with $>48$-hour surgical delay (OR 1.23, p = 0.04). Bohm, et al. [34] established that having surgery within 48 hours demonstrated decreased risk of in-hospital death (HR 0.51, 95\% CI $0.41-0.63$ ) and at 1-year post operation (HR $0.72,95 \%$ CI $0.64-0.80$ ). Colais, et al. [35] stated that those which were operated on within 2 days had a lower 1-year mortality than those operated on after 2 days (HR 0.83, 95\% CI 0.82-0.85). Rosso, et al. [36] reported a decreased 1-year mortality rate with surgery within 48 hours (OR 0.73, p = 0.0392). Cha, et al. [37] demonstrated a significant correlation between both early (30-day) and late (1 year) mortality with delayed surgery ( $>48$ hours). Pincus, et al. [38] established a significantly higher 30-day mortality risk with those operated $>24$ hours compared to $<24$ hours ( $6.5 \%$ vs $5.8 \%, \%$ absolute RD, $0.79 ; 95 \%$ CI $0.23-1.35)$. This group concluded that a wait time of 24 hours may representa "higher risk" threshold. Heyes, et al. [39] reported a significantly increased 1-year mortality risk in those operated $>36$ hours. Maheshwari, et al. [40] recommended 
urgent hip fracture surgery similar to that seen in stroke and myocardial ischaemia after they determined a $5 \%$ higher odds of 1 -year mortality per each 10-hour delay (OR 1.05, 95\% CI 1.02$1.08, p=0.001$ ). Trinh, et al. [41] also concluded that surgery within 48 hours is significantly associated with a decrease in mortality at 1-year post surgery. In March 2018, Chang, et al. [42] published a systematic review and meta-analysis regarding preventable risk factors of mortality after hip fracture surgery. This group described a statistically significant association between increased "time-tosurgery" (>2 days vs < 2 days; OR 1.91, 95\% CI 1.14-3.18, $\mathrm{p}=0.013$ ) and mortality. This association was not present comparing $<24$ hours and $>24$ hours surgical waiting time.

There have also been a number of recent studies which to the contrary, show no association between "time-to-surgery" and mortality risk. Choi, et al. [43] investigated this relationship and reported no increased risk of short or long term mortality after adjusting for potential confounders, whether patients were operated on within 3 days, 3-7 days or $>7$ days. Meessen, et al. [44] recorded mortality rates at 1, 6, 12 and 24 months post operatively. This group established a relationship between male sex, $>85$ years and increased Charlson Comorbidity Index Score and mortality at 2 years, however surgical delay was not found to be a significant factor. Forni, et al. [45] found no significant association between surgical delay and short term mortality risk (30-day). Lizaur Utrilla, et al. [46] investigated early versus late surgery and established that delaying surgery up to 4 days did not result in increased mortality risk at 6 or 12 months, however $>4$ days was associated with greater 1-year mortality risk. Kelly-Pettersson, et al. [47] examined the arbitrarily set time-constraints for surgery post hip fracture and reported an increased risk (12\%) of serious adverse event with every 10-hours of waiting time and increased length of stay of 0.6 days with every 24-hours of waiting time. However, the group found no correlation between "time-to-surgery" and 1-year mortality. Although it is nearly 10 years since Leung, et al. [32] undertook their literature review on this topic, it is clear that at this moment in time, the evidence remains conflicting.

The weekend-effect: Since 2012, there have been 9 large global studies examining the mortality effect of a weekend admission for a patient which has suffered a fragility hip fracture. Two of these papers demonstrated a correlation between weekend admission and increased mortality whilst five reported no difference between weekday and weekend admission. The remaining two suggested a decreased mortality risk when the patient was admitted over the weekend [48-56].

Thomas, et al. [5s7] retrospectively reviewed 2989 hip fracture patients over a 5-year period in the UK. Whilst the group reported no increased mortality with weekend surgery, they reported an increased 30-day mortality risk for all hip fracture patients admitted over the weekend, whether managed operatively or nonoperatively (OR 1.4, 95\% CI 1.02-1.80; $\mathrm{p}=0.032$ ). Kristiansen, et al. [58] retrospectively examined the 30-day mortality risk in a large group of hip fracture patients $(n=25,305)$ in Denmark. This group concluded that the 30-day mortality risk was higher in those admitted at the weekend (OR 1.13, 95\% CI 1.04-1.23).
Sheikh, et al. [59] prospectively assessed 1326 hip fracture patients (UK) for differences in admission days and mortality risk and concluded there was no difference between weekday or weekend admission with regards to 30-day, 90-day or 1-year mortality risk. Nijland, et al. [60] retrospectively collected mortality information with respect to 1803 patients in a hip fracture cohort in the Nederlands. This group recorded no association between weekend admission and increased 30-day or 1-year mortality. Mathews, et al. [61] prospectively collected information with respect to 816 hip fractures patients in a teaching hospital in the UK. This group concluded that weekend admission was not associated with increased risk of 30-day or 120-day mortality. Daugaard, et al. [62] retrospectively reviewed data collected on 38,020 hip fracture patients admitted over an 8-year period in Denmark. Their investigations showed that there was no difference in mortality risk in their large cohort between those admitted during the weekdays versus the weekends. Neuberger, et al. [63] studied fragility hip fracture related 30-day mortality using data from 52, 599 patients presenting to NHS hospitals (162 units) over 2014. Specifically assessing for differences in outcomes between those admitted on weekends versus weekdays, this group found no difference between both groups.

Boylan, et al. [64] retrospectively analyzed 344,989 hip fracture patients admitted over a 13-year period in an orthopedic department in New York, USA. This group reported decreased short term mortality in patients admitted at the weekend versus those admitted during the weekdays (OR 0.94, 95\% CI 0.89-0.99). Nandra, et al. [65] examined a group of 2060 hip fracture patients retrospectively treated in a UK hospital. They reported marginally lower 30-day mortality in those admitted at the weekend versus weekday (9.7\% vs $10.2 \%$ ), however this finding was not statistically significant (OR 0.94, 95\% CI 0.67-1.32). The group found "no significant weekend effect".

These studies do not present a conclusive significant repeated "weekend effect". The above research articles report heterogenous and conflicting findings. The outcome data for some $\sim 470,000$ patients are presented above. Whilst 5 of the 9 studies include $<3000$ patients per cohort, the remaining 4 large studies included $25,308,38,020,52,599$ and 344,989 patients, each of which reported an increased risk, 2 studies showing no difference and a decreased mortality risk respectively.

\section{Conclusion}

There are a multitude of research studies on fragility hip fractures and those variables which are associated with an increased risk of mortality following a fragility hip fracture. I have summarized the most up-to-date literature above on gender, age, nursing home residency, time-to-surgery and the "weekend effect". Whilst there appears to be agreement on the impact of male gender, increasing age and nursing home residency on mortality, more research is required to delineate the relationship between time-tosurgery and the "weekend effect" and mortality at 1-year.

\section{Acknowledgement}

None. 


\section{Conflict of Interest}

No Conflict of Interest.

\section{References}

1. Neuburger J, Currie C, Wakeman R, Tsang C, Plant F, et al. (2015) The impact of a national clinician-led audit initiative on care and mortality after hip fracture in England: an external evaluation using time trends in non-audit data. Med Care 53(8): 686-691.

2. Moran CG, Wenn RT, Sikand M, Taylor AM (2005) Early mortality after hip fracture: is delay before surgery important? J Bone Joint Surg Am 87(3): 483-489.

3. Moppett IK, Parker M, Griffiths R, Bowers T, White SM, et al. (2012) Nottingham Hip Fracture Score: longitudinal and multi-assessment. $\mathrm{Br}$ J Anaesth 109(4): 546-550.

4. Karres J, Heesakkers NA, Ultee JM, Vrouenraets BC (2015) Predicting 30-day mortality following hip fracture surgery: evaluation of six risk prediction models. Injury 46(2): 371-377.

5. Nijmeijer WS, Folbert EC, Vermeer M, Slaets JP, Hegeman JH (2016) Prediction of early mortality following hip fracture surgery in frail elderly: The Almelo Hip Fracture Score (AHFS). Injury 47(10): 21382143.

6. Choi JY, Cho KJ, Kim SW, Yoon SJ, Kang MG, et al. (2017) Prediction of Mortality and Postoperative Complications using the HipMultidimensional Frailty Score in Elderly Patients with Hip Fracture. Sci Rep 7:42966.

7. Tsang C, Boulton C, Burgon V, Johansen A, Wakeman R, et al. (2017) Predicting 30-day mortality after hip fracture surgery: Evaluation of the National Hip Fracture Database case-mix adjustment model. Bone Joint Res 6(9): 550-556.

8. Karres J, Kieviet N, Eerenberg JP, Vrouenraets BC (2018) Predicting Early Mortality After Hip Fracture Surgery: The Hip Fracture Estimator of Mortality Amsterdam. J Orthop Trauma 32(1): 27-33.

9. Jiang HX, Majumdar SR, Dick DA, Moreau M, Raso J, et al. (2005) Development and initial validation of a risk score for predicting inhospital and 1-year mortality in patients with hip fractures. J Bone Miner Res 20(3): 494-500.

10. Holt G, Smith R, Duncan K, Finlayson DF, Gregori A (2008) Early mortality after surgical fixation of hip fractures in the elderly: an analysis of data from the scottish hip fracture audit. J Bone Joint Surg Br 90(10): 13571363.

11. Irish Hip Fracture Database National Report (2017) Available from: https://www.noca.ie/wp-content/uploads/2015/04/Irish-HipFracture-Database-National-Report-2016-FINAL.pdf.

12. Rimmer A (2017) Weekend Effect is not reduced by clinical standards designed to tackle it. BMJ 359: j5185.

13. Seven Day Services in the NHS: National Health Service (2017) Available from: https://improvement.nhs.uk/resources/seven-day-services/.

14. Johansen A, Golding D, Brent L, Close J, Gjertsen JE, et al. (2017) Using national hip fracture registries and audit databases to develop an international perspective. Injury 48(10): 2174-2179.

15. Forsen L, Omsland TK, Sogaard AJ, Meyer HE, Holvik K, et al. (2018) Does the Association of Comorbidity with 1-Year Mortality After Hip Fracture Differ According to Gender? The Norwegian Epidemiologic Osteoporosis Studies (NOREPOS). J Am Geriatr Soc 66(3): 553-558.

16. Omsland TK, Emaus N, Tell GS, Magnus JH, Ahmed LA, et al. (2014) Mortality following the first hip fracture in Norwegian women and men (1999-2008) A NOREPOS study. Bone 63: 81-86.

17. Kristensen PK, Johnsen SP, Mor A, Thillemann TM, Pedersen AB (2017) Is the higher mortality among men with hip fracture explained by sexrelated differences in quality of in-hospital care? A population-based cohort study. Age Ageing 46(2):193-199.

18. Liu Y, Wang Z, Xiao W (2018) Risk factors for mortality in elderly patients with hip fractures: a meta-analysis of 18 studies. Aging Clin Exp Res 30(4): 323-330.
19. Haentjens P, Magaziner J, Colon Emeric CS, Vanderschueren D, Milisen $\mathrm{K}$, et al. (2010) Meta-analysis: excess mortality after hip fracture among older women and men. Ann Intern Med 152(6): 380-390.

20. Sheikh HQ, Hossain FS, Aqil A, Akinbamijo B, Mushtaq V, et al. (2017) A Comprehensive Analysis of the Causes and Predictors of 30-Day Mortality Following Hip Fracture Surgery. Clin Orthop Surg 9(1): 10-18.

21. Muraki S, Yamamoto S, Ishibashi H, Nakamura K (2006) Factors associated with mortality following hip fracture in Japan. J Bone Miner Metab 24(2): 100-104.

22. Ariza Vega P, Kristensen MT, Martin-Martin L, Jimenez Moleon JJ (2015) Predictors of long-term mortality in older people with hip fracture. Arch Phys Med Rehabil 96(7): 1215-1221.

23. Paksima N, Koval KJ, Aharanoff G, Walsh M, Kubiak EN, et al. (2008) Predictors of mortality after hip fracture: a 10-year prospective study. Bull NYU Hosp Jt Dis 66(2): 111-117.

24. Hu F, Jiang C, Shen J, Tang P, Wang Y (2012) Preoperative predictors for mortality following hip fracture surgery: a systematic review and metaanalysis. Injury 43(6): 676-685.

25. Forsen L, Sogaard AJ, Meyer HE, Edna T, Kopjar B (1999) Survival after hip fracture: short- and long-term excess mortality according to age and gender. Osteoporos Int 10(1): 73-78.

26. Roche JJ, Wenn RT, Sahota O, Moran CG (2005) Effect of comorbidities and postoperative complications on mortality after hip fracture in elderly people: prospective observational cohort study. BMJ 331(7529): 1374.

27. Kilci O, Un C, Sacan O, Gamli M, Baskan S, et al. (2016) Postoperative Mortality after Hip Fracture Surgery: A 3 Years Follow Up. PLoS One 11(10): e0162097.

28. Padron Monedero A, Lopez Cuadrado T, Galan I, Martinez Sanchez EV, Martin P, et al. (2017) Effect of comorbidities on the association between age and hospital mortality after fall-related hip fracture in elderly patients. Osteoporos Int 28(5): 1559-1568.

29. Holvik K, Ranhoff AH, Martinsen MI, Solheim LF (2010) Predictors of mortality in older hip fracture inpatients admitted to an orthogeriatric unit in oslo, norway. J Aging Health 22(8): 1114-1131.

30. Khan MA, Hossain FS, Ahmed I, Muthukumar N, Mohsen A (2013) Predictors of early mortality after hip fracture surgery. Int Orthop 37(11): 2119-2124.

31. Hannan EL, Magaziner J, Wang JJ, Eastwood EA, Silberzweig SB, et al. (2001) Mortality and locomotion 6 months after hospitalization for hip fracture: risk factors and risk-adjusted hospital outcomes. JAMA 285(21): 2736-2742.

32. Leung F, Lau TW, Kwan K, Chow SP, Kung AW (2010) Does timing of surgery matter in fragility hip fractures? Osteoporos Int 21(4): S529534.

33. Nyholm AM, Gromov K, Palm H, Brix M, Kallemose T, et al. (2015) Time to Surgery Is Associated with Thirty-Day and Ninety-Day Mortality After Proximal Femoral Fracture: A Retrospective Observational Study on Prospectively Collected Data from the Danish Fracture Database Collaborators. J Bone Joint Surg Am 97(16): 1333-1339.

34. Bohm E, Loucks L, Wittmeier K, Lix LM, Oppenheimer L (2015) Reduced time to surgery improves mortality and length of stay following hip fracture: results from an intervention study in a Canadian health authority. Can J Surg 58(4): 257-263.

35. Colais P, Di Martino M, Fusco D, Perucci CA, Davoli M (2015) The effect of early surgery after hip fracture on 1-year mortality. BMC Geriatr 15: 141.

36. Rosso F, Dettoni F, Bonasia DE, Olivero F, Mattei L, et al. (2016) Prognostic factors for mortality after hip fracture: Operation within 48 hours is mandatory. Injury 47(4): S91-S97.

37. Cha YH, Ha YC, Yoo JI, Min YS, Lee YK, et al. (2017) Effect of causes of surgical delay on early and late mortality in patients with proximal hip fracture. Arch Orthop Trauma Surg 137(5): 625-630.

38. Pincus D, Ravi B, Wasserstein D, Huang A, Paterson JM, et al. (2017) Association Between Wait Time and 30-Day Mortality in Adults Undergoing Hip Fracture Surgery. JAMA 318(20): 1994-2003. 
39. Heyes GJ, Tucker A, Marley D, Foster A (2017) Predictors for 1-year mortality following hip fracture: a retrospective review of 465 consecutive patients. Eur J Trauma Emerg Surg 43(1): 113-119.

40. Maheshwari K, Planchard J, You J, Sakr WA, George J, et al. (2018) Early Surgery Confers 1-Year Mortality Benefit in Hip-Fracture Patients. J Orthop Trauma 32(3): 105-110.

41. Trinh LTT, Achat H, Loh SM, Pascoe R, Asarreh H et al. (2018) Meeting Management Standards and Improvement in Clinical Outcomes Among Patients with Hip Fractures. J Healthc Qual 40(6): 336-343.

42. Chang W, Lv H, Feng C, Yuwen P, Wei N, et al. (2018) Preventable risk factors of mortality after hip fracture surgery: Systematic review and meta-analysis. Int J Surg 52: 320-328.

43. Choi HJ, Kim E, Shin YJ, Choi BY, Kim YH, et al. (2014) The timing of surgery and mortality in elderly hip fractures: A retrospective, multicenteric cohort study. Indian J Orthop 48(6): 599-604.

44. Meessen JM, Pisani S, Gambino ML, Bonarrigo D, van Schoor NM, et al. (2014) Assessment of mortality risk in elderly patients after proximal femoral fracture. Orthopedics 37(2): e194-e200.

45. Forni S, Pieralli F, Sergi A, Lorini C, Bonaccorsi G, et al. (2016) Mortality after hip fracture in the elderly: The role of a multidisciplinary approach and time to surgery in a retrospective observational study on 23,973 patients. Arch Gerontol Geriatr 66: 13-17.

46. Lizaur Utrilla A, Martinez Mendez D, Collados Maestre I, Miralles Munoz FA, Marco Gomez L, et al. (2016) Early surgery within 2 days for hip fracture is not reliable as healthcare quality indicator. Injury 47(7): 1530-1535.

47. Kelly Pettersson P, Samuelsson B, Muren O, Unbeck M, Gordon M, et al. (2017) Waiting time to surgery is correlated with an increased risk of serious adverse events during hospital stay in patients with hip-fracture: A cohort study. Int J Nurs Stud $69: 91-97$.

48. Brozek W, Reichardt B, Kimberger O, Zwerina J, Dimai HP, et al. (2014) Mortality after hip fracture in Austria 2008-2011. Calcif Tissue Int 95(3): 257-266.

49. Marques A, Lourenco O, da Silva JA, Portuguese (2015) Working Group for the Study of the Burden of Hip Fractures in P. The burden of osteoporotic hip fractures in Portugal: costs, health related quality of life and mortality. Osteoporos Int 26(11): 2623-2630.

50. Klop C, Welsing PM, Cooper C, Harvey NC, Elders PJ, et al. (2014) Mortality in British hip fracture patients, 2000-2010: a populationbased retrospective cohort study. Bone 66: 171-177.

51. Poenaru DV, Prejbeanu R, Iulian P, Haragus H, Popovici E, et al. (2014) Epidemiology of osteoporotic hip fractures in Western Romania. Int Orthop 38(11): 2329-2334.
52. Tucker A, Donnelly KJ, McDonald S, Craig J, Foster AP, et al. (2017) The changing face of fractures of the hip in Northern Ireland: a 15-year review. Bone Joint J 99-B (9): 1223-1231.

53. Folbert EC, Hegeman JH, Vermeer M, Regtuijt EM, van der Velde D, et al. (2017) Improved 1-year mortality in elderly patients with a hip fracture following integrated orthogeriatric treatment. Osteoporos Int 28(1): 269-277.

54. Grech S CS (2016) Osteoporotic hip fractures - Three year follow up morality rate in Malta. Malta Medical Journal 28(3): 5-10.

55. Haugan K, Johnsen LG, Basso T, Foss OA (2017) Mortality and readmission following hip fracture surgery: a retrospective study comparing conventional and fast-track care. BMJ Open 7(8): e015574.

56. Magnusson KA, Gunnarsson B, Sigurdsson GH, Mogensen B, Olafsson Y, et al. (2016) Treatment and outcome of patients with hip fracture. Laeknabladid 102(3): 119-125.

57. Thomas CJ, Smith RP, Uzoigwe CE, Braybrooke JR (2014) The weekend effect: short-term mortality following admission with a hip fracture. Bone Joint J 96-B (3): 373-378.

58. Kristiansen NS, Kristensen PK, Norgard BM, Mainz J, Johnsen SP (2016) Off-hours admission and quality of hip fracture care: a nationwide cohort study of performance measures and 30-day mortality. Int J Qual Health Care 28(3): 324-331.

59. Sheikh HQ, Aqil A, Hossain FS, Kapoor H (2017) There is no weekend effect in hip fracture surgery - A comprehensive analysis of outcomes. Surgeon 16(5): 259-264.

60. Nijland LMG, Karres J, Simons AE, Ultee JM, Kerkhoffs G, et al. (2017) The weekend effect for hip fracture surgery. Injury 48(7): 1536-1541.

61. Mathews JA, Vindlacheruvu M, Khanduja V (2016) Is there a weekend effect in hip fracture patients presenting to a United Kingdom teaching hospital? World J Orthop 7(10): 678-686.

62. Daugaard CL, Jorgensen HL, Riis T, Lauritzen JB, Duus BR, et al. (2012) Is mortality after hip fracture associated with surgical delay or admission during weekends and public holidays? A retrospective study of 38,020 patients. Acta Orthop 83(6): 609-613.

63. Neuburger J, Currie C, Wakeman R, Georghiou T, Boulton C, et al. (2018) Safe working in a 7-day service. Experience of hip fracture care as documented by the UK National Hip Fracture Database. Age Ageing 47(5): 741-745.

64. Boylan MR, Rosenbaum J, Adler A, Naziri Q, Paulino CB (2015) Hip Fracture and the Weekend Effect: Does Weekend Admission Affect Patient Outcomes? Am J Orthop (Belle Mead NJ) 44(10): 458-464.

65. Nandra R, Pullan J, Bishop J, Baloch K, Grover L (2017) Comparing mortality risk of patients with acute hip fractures admitted to a major trauma centre on a weekday or weekend. Sci Rep 7(1): 1233. 